\title{
POBREZA EN UN REASENTAMIENTO VOLUNTARIO DE POBLACIÓN DESPLAZADA: CASO PATIO GRANDE $^{1}$
}

\author{
POVERTY IN THE VOLUNTARY RESETTLEMENT OF DISPLACED POPUILATION: \\ PATIO GRANDE CASE
}

Por: Camilo Rey Sabogal*

Artículo Recibido: Mayo 23 de 2010. Artículo Aprobado: Julio 9 de 2010. Páginas: 58-83

*CAMILO REY SABOGAL

Economista (Universidad

de Cartagena). Magíster

en Ciencias Económicas (Universidad Nacional

de Colombia). Docente $e$ investigador adscrit al Observatorio de Desplazamiento Forzado y Derechos Humanos de la Facultad de Ciencias Sociales y Educación de la Universidad de Cartagena(Colombia). E-mail: reymilo@gmail.com

Artículo tipo 1 de investigación científica y tecnológica según clasificación Colciencias.

${ }^{1}$ El articulo presenta resultados de la investigación "Factores que facilitan u obstaculizan el logro de los Objetivos de Desarrollo de Milenio desde un enfoque de derecho en las familias reasentadas: Caso Patio Grande", financiada por la Universidad de Cartagena mediante de la Resolución 2252 de 2009.

\section{RESUMEN}

En el 2003 un grupo de 39 familias en condición de desplazamiento aceptaron la propuesta del Gobierno colombiano para reasentarse de forma voluntaria, segura y digna en la finca Patio Grande (San Jacinto- Bolívar). Sin embargo recibir la tierra no significa eliminar la condición de desplazado de las víctimas, también es necesario que se consolide y estabilice su situación socioeconómica en el nuevo lugar. De acuerdo con la Corte Constitucional, una señal de dicha estabilización, es la superación de la indigencia (meta parcial) y de la pobreza (meta definitiva). Este documento pretende evaluar la situación de Patio Grande frente a estas dos variables. El análisis de información recolectada indica que, después de siete años de reasentamiento ningún hogar ha logrado superar la pobreza y el 76\% aun recibe ingresos inferiores a la línea de indigencia. Estos resultados son consecuencia de las condiciones de vulnerabilidad y de marginalización que padecen las víctimas por su calidad de desplazados, de campesinos y de reasentados en la zona rural de un municipio muy pobre, que además es ajeno a sus múltiples y diversas raíces.

Palabras clave: Desplazamiento forzado, Reasentamiento, Pobreza, Indigencia, Conflicto armado.

\section{ABSTRACT}

In 2003 a group of 39 families living in displacement conditions, accepted the proposal of the Colombian Government to resettle voluntarily in safety and dignity Patio Villa Grande (San Jacinto, Bolivar). However receiving the land, does not mean eliminating the status of displaced victims, it is also necessary to consolidate and stabilize the socio-economic situation in the new place. According to the Constitutional Court, a sign of the stabilization is to overcome indigence (partial target) and poverty (ultimate goal). This article pretends to evaluate the situation of Patio Grande against these two variables. The analysis of collected data indicates that, after seven years of resettlement none of these families has overcome any household poverty and 76\% are still receiving income below the poverty line. These results are a consequence of the vulnerability and marginalization suffered by displaced victims, resettled farmers in the rural area of poor municipality, who are also strangers to their diverse roots.

Keywords: Forced displacement, resettlement, poverty, indigence, armed conflict. 


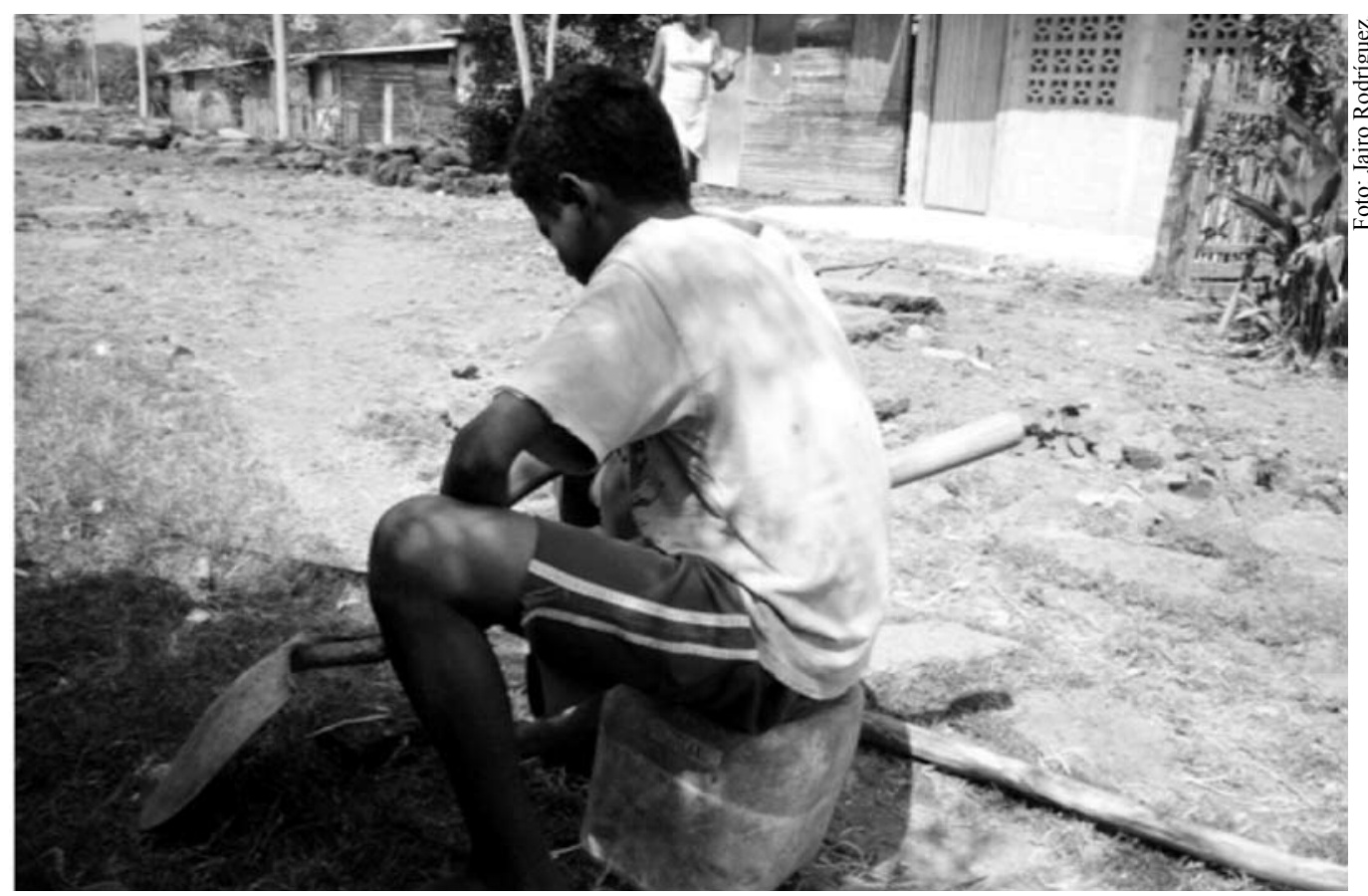

Menor trabajador. Patio Grande (Bolívar) 2010

\section{Introducción}

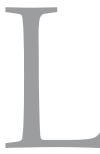

a Ley 387 de 1997 asigna responsabilidades al Estado para la atención, la prevención y la cesación del desplazamiento forzado, precisa que la condición de desplazado por la violencia, termina solo cuando se logra la consolidación y estabilización socioeconómica, bien sea en su lugar de origen o en las zonas de reasentamiento.

La sentencia T-602 de 2003 de la Corte Constitucional establece los criterios para dicha consolidación y estabilización socioeconómica y define que un hogar cesa de ser desplazado cuando: i) se contrarrestan los riesgos de empobrecimiento; ii) se promueve el acceso a la tierra; iii) el hogar accede a empleo en condiciones dignas, soluciones de vivienda, atención médicaasistencial integral, nutrición adecuada y educación; iv) el hogar es capaz de generar ingresos; y v) cuenta con una participación política efectiva.

¿Qué alternativas ofrece la ley al hogar desplazado sobre el lugar geográfico para el inicio el proceso de estabilización socioeconómica de cada familia? Una opción es integrar al hogar en el municipio de recepción, otra es retornar al municipio de origen y la última opción es reasentar ${ }^{2}$ la familia en un nuevo municipio diferente al de expulsión y al de reasentamiento temporal. Las tres opciones deben ser en condiciones de voluntariedad, dignidad y seguridad.

La opción de integración en el municipio de recepción permite aprovechar

Palobra No. 11. Septiembre de 2009 - Agosto de 2010

${ }^{2}$ En algunos textos se emplea la palabra reubicación para referirse a este tipo de reasentamiento. ACNUR define reasentamiento como la "selección y transferencia de refugiados desde un Estado en el cual ellos han buscado protección a un tercer Estado que ha aceptado admitirles que ha aceptado admitirles -como refugiados- con estatuto de residencia permanente" (ACNUR, 2004). Se debe aclarar que el concepto de refugiado hace alusión a las personas que cruzan las fronteras nacionales para salvaguardar su vida miensalvaguardar su vida, miense habla de des- plazamiento forzado cuando la persona migra por los mis-
mos motivos, pero dentro del territorio nacional. 
3 Datos suministrados en Entrevista de marzo de 2009 por Ayda Velásquez asesora de la Secretaría del Interior de la Gobernación de Bolivar.

${ }^{4}$ DANE - Censo 2005. la infraestructura de servicios sociales y colectivos que posee previamente el municipio, pero implica "la adaptación de la población a las nuevas condiciones espaciales, culturales, sociales y económicas" (Jiménez, 2008). El retorno, por el contrario, facilita la recuperación de dichas condiciones en los lugares de origen, pero debe ser producto de una solución concertada que exige un mayor esfuerzo estatal en el restablecimiento de la seguridad y la eliminación de las causas que motivaron el desplazamiento original. Finalmente la opción de reasentamiento se refiere a la situación en la cual las personas que previamente habían sido desplazadas temiendo por su vida, deciden voluntariamente ubicarse de forma definitiva y digna en otro lugar, bajo la protección del Estado. Este reasentamiento voluntario interno puede darse bajo dos modalidades, una ubicando a las familias en la cabecera del municipio, donde gozarán de la infraestructura institucional y socioeconómica de la zona urbana, pero donde deberán integrarse en la dinámica social del municipio. La segunda, ubicando a las familias en una zona rural (donde puede ser más fácil la entrega de tierras), pero deberán constituir un nuevo caserío o vereda que normalmente carece de la infraestructura mencionada.

Apoyadas en estos elementos entre el año 2003 y el 2004, 39 familias $^{3}$ asentadas en la ciudad de Cartagena, pero desplazadas desde ocho departamentos diferentes decidieron aceptar la propuesta del Gobierno Nacional de reasentarse en la finca Patio Grande, un terreno de 525 hectáreas ubicado políticamente en San Jacinto (Bolívar). El territorio propuesto se localiza en una zona tradicionalmente agrícola. Además la finca se ubica sobre una de las orillas de la carretera que enlaza los municipios de San Jacinto y El Carmen de Bolívar, de tal forma que la distancia más extensa, hasta un centro urbano es de menos de $10 \mathrm{~km}$, facilitando su conexión con los mercados subregionales.

Sin embargo, la ubicación también presenta varias dificultades. Las condiciones sociales y económicas de las zonas rurales del departamento y en particular de San Jacinto son extremadamente precarias. De hecho este municipio tiene los niveles más altos de Bolívar en analfabetismo, carencia de servicios públicos y pobreza4 ${ }^{4}$. Esta situación municipal alerta sobre la posible inexistencia de las condiciones sociales mínimas para que las familias reasentadas en Patio Grande superen los riesgos de empobrecimiento y logren una consolidación y estabilización socioeconómica. En este orden de ideas, se pretende indagar sobre los avances de la comunidad de Patio Grande en la superación de la pobreza como condición mínima para la estabilización socioeconómica. 


\section{Antecedentes conceptuales: reasentamiento y pobreza}

Con el apoyo del Banco Mundial, el estadounidense Michael Cernea (1997), adelantó una serie de evaluaciones sobre el bienestar de las poblaciones que han tenido involuntariamente que reasentarse por la ejecución de proyectos de desarrollo ${ }^{5}$. Encuentra que a pesar de la diversidad, existe un patrón de riesgos comunes que enfrentan estas comunidades y que pueden conducirlas a la pobreza. A partir de ello, formula un modelo de detección de riesgos y oportunidades de reconstrucción que anticipa los principales efectos del desplazamiento, que explica las respuestas de conducta de las personas desplazadas y que guía en el reestablecimiento de los medios de vida. Los riesgos identificados son: pérdida de la tierra, pérdida del empleo, pérdida del hogar, marginalización, aumento de enfermedad, inseguridad alimentaria, pérdida de acceso a bienes colectivos y desarticulación de los redes sociales, de los vínculos informales de ayuda y del sentido de comunidad. Se debe tener en cuenta, además, que los riesgos afectan de manera diferente a cada grupo, por lo cual en algunos casos, como los menores de edad, los discapacitados o las embarazadas, entre otros, puede ser mayor la probabilidad de empobrecimiento.

Más adelante Robert Muggah por un lado y María Mejía por otro, utilizan el modelo de Cernea, para evaluar los riesgos en población desplazada por violencia y reasentada voluntariamente y concluyen que si no se planifican cuidadosamente, los dos tipos de reasentamiento pueden llevar al empobrecimiento y pueden representar violaciones explícitas a los derechos humanos. Pero adicionalmente el caso de reasentamiento voluntario de población desplazada, conlleva otros riesgos, que puede incrementar la probabilidad de caer no sólo en la pobreza, sino en condiciones de indigencia. Estos riesgos adicionales, son entre otros, la pérdida de miembros del hogar, daños en la salud y la integridad física y mental y la destrucción total y parcial del tejido social, hechos que se constituyen en pérdidas irreparables para la población que experimenta el reasentamiento que profundizan la pobreza y que aplazan las urgencias por su superación (Muggah, 2000 y Mejía, 2000).

Mejía agrega como variable de riesgo adicional el hecho que las causas que originan el desplazamiento no han sido eliminadas, por lo tanto el éxito del reasentamiento "depende en cierta medida, del avance en los acuerdos de paz,... así como de cambios profundos en el sistema de acceso a la tierra, la creación de
${ }^{5}$ El reasentamiento puede ser involuntario o voluntario. Es involuntario cuando las personas están obligadas a desplazarse y ubicarse en otro lugar diferente al origen por razones de violencia, por desastres naturales o por la ejecución de proyectos de desarrollo. En este último caso, el desplazamiento y reasentamiento es planificado y ejecutado por el Estado y/o por las empresas que dirigen el proyecto. Mientras que el ocasionado por la violencia carece de planificación $y$ obedece al temor thich y obedece al temor $y$ huida por salvaguardar la vida de los ataques de los actores armados legales e ilegales. 
empleo, la distribución de ingresos y oportunidades y otros factores de alcance nacional" (op. cit.) .

Debido a los efectos que describe Cernea y que amplían los autores mencionados, no es suficiente conducir las familias a otro lugar en calidad de reasentado, es necesario restablecer lo perdido por los efectos señalados, lo que implica efectuar acciones dirigidas a contrarrestar los riesgos de empobrecimiento. En palabras de la Corte: "el acceso efectivo de los desplazados a bienes y servicios básicos, así como la garantía de sus derechos y libertades fundamentales se traducen en el restablecimiento y, por tanto, en la cesación de la situación de desplazamiento forzado interno"6.

Justamente, la Corte Constitucional en el $2004^{7}$ afirmó que a la población desplazada, se le han violado de forma sistemática sus derechos a una vida digna, a la integridad personal, a la igualdad, de petición, al trabajo, a la salud, a la seguridad social, a la educación, al mínimo vital y a la debida protección especial a las personas de la tercera edad, a la mujer cabeza de familia y a los niños, entre otros. Adicionalmente, el alto tribunal les recordó a las autoridades que los retornos o reasentamientos deben ser voluntarios y en condiciones de seguridad y dignidad.

De forma complementaria la Corte emite el auto 233 de 2007, por medio del cual define los niveles que debe adquirir cada indicador de goce efectivo de derechos para evidenciar el cese de la condición de desplazamiento. En el tema de generación de ingresos y reducción de la pobreza, establece como meta transitoria que "el hogar posee al menos una fuente de ingresos autónoma y su ingreso supera como mínimo la línea de indigencia" y como meta definitiva que "el hogar posee al menos una fuente de ingresos autónoma y su ingreso se ubica por encima de la línea de pobreza".

\section{Antecedentes empíricos}

La mayoría de la población colombiana refugiada en el exterior se ubica en Ecuador, por ello Netherlands Interdisciplinary Demographic Institute tomó como muestra ese país para el diagnóstico mundial de los Objetivos de Desarrollo del Milenio en población refugiada, asilada y desplazada. Los hallazgos más importantes fueron que la mitad de los colombianos refugiados recibe menos de un dólar diario, además padecen graves problemas

${ }^{6}$ Corte Constitucional. Sentencia T-602 de 2003.

${ }^{7}$ Corte Constitucional. Sentencia T-025 de 2004. de seguridad alimentaria y registran bajas tasas de acceso a acueducto y saneamiento básico (2006). 
A nivel nacional, el diagnóstico más importante, por cobertura, metodología y carga institucional es el llevado a cabo por la Comisión de Seguimiento a la Política Pública sobre el Desplazamiento Forzado ${ }^{8}$. Dentro de sus resultados, es clave señalar que la población desplazada reasentada involuntariamente está soportando problemas extremos de pobreza y hambre, ya que una cuarta parte de los menores de cinco años han reportado desnutrición y el 98\% de los encuestados recibe ingresos que lo ubican por debajo de la línea de pobreza (Garay, 2008).

La profesora Ana Ibáñez, de la Universidad de los Andes, también ha mostrado evidencia cuantitativa del empobrecimiento de las víctimas del desplazamiento forzado reasentadas involuntariamente. Demuestra por ejemplo, que tanto el consumo agregado como el ingreso de la población desplazada descienden significativamente en el municipio de recepción y que luego de mucho tiempo los desplazados no logran superar dichas condiciones (2006).

Sobre población retornada, se destaca el trabajo del Instituto Latinoamericano de Servicios Legales Alternativos, que desde la investigación cualitativa evalúa los resultados de las estrategias de retorno del gobierno de Álvaro Uribe. El Instituto concluyó que si bien los retornos resultaban ser voluntarios, estos no se han efectuado dentro del marco de los Principios Rectores para los desplazamientos internos, por lo cual estos grupos poblaciones no han perdido su calidad de desplazados, hasta tanto no se haga efectivo el restablecimiento de sus derechos y la consolidación y estabilización socioeconómica (2006).

Como se indicó anteriormente, existen pocos intentos de diagnóstico de reasentamientos voluntarios. Dentro estos, se destaca el trabajo de Muggah, que apoyado en el modelo de Cernea y en la investigación cualitativa, examina los reasentamientos de La Miel en el Tolima y Las Dudas en Córdoba. Concluye que la planificación y el apoyo estatal fueron mínimos y que la población detecta como riesgos fundamentales, la pérdida de tierra, el aumento de la morbilidad, la pérdida de la educación, la pérdida de los servicios públicos y comunes y la presencia de la violencia (op. cit.). Un resultado similar encontró el CODHES en La Miel y agrega que en el gobierno "primó más el criterio de reubicar en el sentido de trasladar de un lugar a otro que el de reasentamiento, entendido como la construcción concertada de soluciones colectivas a partir de un concepto de reparación desde los derechos conculcados en un marco de equidad y justicia" (2000).

Palobra No. 11. Septiembre de 2009 - Agosto de 2010
${ }^{8}$ Organismo surgido por encargo de la Corte Constitucional y cuya misión es realizar periódicamente la verificación del goce efectivo de derechos de la población desplazada. 


\section{Metodología}

Dado el reducido tamaño de la población no hubo selección de muestra, el estudio se diseñó como censo y se aplicó a todos los habitantes de Patio Grande que residían en el periodo de recolección de información. Para la construcción del cuestionario el grupo tomó como marco de referencia las variables requeridas para el cálculo de indicadores de reconocimiento nacional e internacional con el fin de garantizar el análisis comparativo de los resultados. Los resultados del Censo de Población Reasentada en Patio Grande (CRPG) 2010 están conformados por respuestas a 103 preguntas que consultan información sobre las características de la vivienda, la composición del hogar, el origen del desplazamiento, variables demográficas y aspectos socioeconómicos tales como: educación, salud, alimentación, empleo, ingresos, actividades económicas, embarazos y percepciones acerca del apoyo recibido por el Estado y las expectativas de futuro cercano. El 46\% de las preguntas se formularon por hogar y las restantes por persona.

Igualmente, se llevó a cabo la técnica de grupos focales. Para ello se organizaron seis grupos conformados por personas mayores de edad residentes en la comunidad y agrupados en seis categorías de análisis: vivienda, salud, educación, generación de ingresos, organización comunitaria y reparación. Para la orientación y delimitación de la discusión se desarrolló la modalidad de entrevista abierta grupal semiestructurada con preguntas orientadoras que apuntaron a identificar, para cada categoría, percepciones construidas colectivamente sobre los obstáculos, las fortalezas, la valoración del cambio y las expectativas.

\section{Resultados}

A pesar del tamaño reducido de habitantes, en Patio Grande residen pobladores de ocho departamentos diferentes y aunque algunos comparten origen de expulsión, no coinciden en el año de desplazamiento. Cuando recibieron la oferta del reasentamiento todos los hogares residían en Cartagena, pero para algunos de estos, la ciudad no era el primer lugar de recepción, y para otros, este era su segundo intento de reasentamiento. Por todo esto, previo al hecho violento las familias no se conocían entre sí, y sus lazos solo empezaron a surgir en Cartagena o en otros municipios donde se asentaron inicialmente. 


\section{Gráfico 1. Departamento expulsor de la población reasentada en Patio Grande}

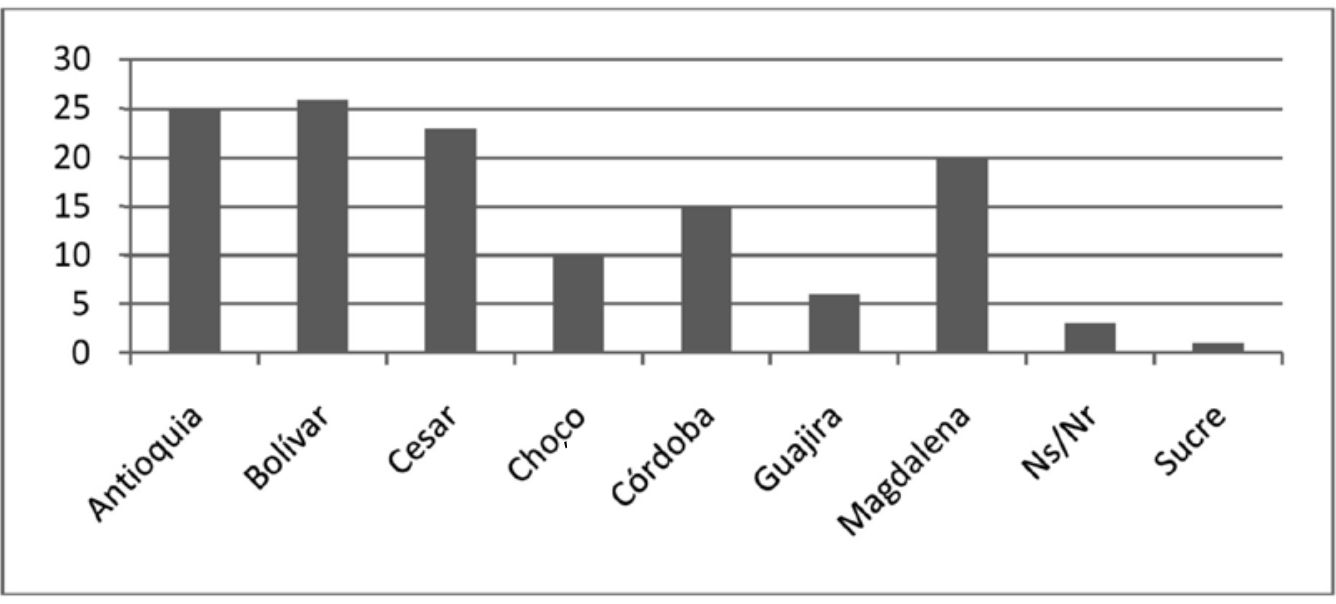

Fuente: Cálculos del autor con base en CRPG - Cartagena, 2010

Esto sugiere la presencia de una gran diversidad en sus tradiciones y costumbres que pueden limitar la articulación de redes comunitarias que promuevan proyectos colectivos de desarrollo. Es así como se encontró, por ejemplo, habitantes con vocación agraria de zonas cálidas y de zonas templadas, con vocación ganadera extensiva e intensiva y otros con vocación piscícola de río y de mar.

Las diferencias dentro de esta pequeña vereda pueden ser más fuertes por la variedad en el tiempo de antigüedad del episodio que causó el desplazamiento en cada familia. Mientras el 56\% de los encuestados accedió al reasentamiento el mismo año o un año anterior al desplazamiento, el 22\% llevaba de dos a tres años de expulsión y el 21\% restante llevaba cuatro o más años en situación de desplazamiento. Esta variable es importante porque los efectos y los riesgos de empobrecimiento tienden a ser más graves cuando el tiempo transcurrido sin recibir una solución de reparación y restablecimiento es mayor (Cernea, op. cit.) .

Un elemento adicional que implica más diversidad es el grupo armado ilegal que declaran como responsable del desplazamiento. El 43\% de los hogares manifiestan haber huido por acciones exclusivas de los grupos paramilitares, el 6.6\% por acciones exclusivas de grupos guerrilleros, el 20\% declara como autores a los dos grupos, mientras que el 36\% no identifica el responsable.

Si bien los datos de desplazamiento arrojan fuertes variaciones entre hogares, existen otros elementos que tienden a asemejar sus procesos de persecusión. El 
temor por la vida, los riesgosos recorridos para salvaguardarse y la condición de miseria resultante tienden a ser elementos comunes entre cada uno de estos hogares, tal como se lee en algunos apartes de las entrevistas.

“Unos paracos llegaron que no se qué, que no sé cuándo, que pitos, que flauta entonces vienen a coger a uno que no sabe ni por donde va la tabla, y que uno es de la guerrilla. Entonces se meten los soldados los paracos y la guerrilla unos manes que vienen armados hasta los dientes icómo hace uno? Tiene que estar humillao... Llegaron a la casa me sacaron con el hermano, nos llevaron a un monte, $y$ al hermano mío me lo mataron, a mí me tenían mareado con que me iban a matar, de pronto como me vieron muy viejo dijeron: no, vamos a dejar este viejo que se vaya. Bueno y yo me vine, entonces la mujer me dijo, aja te mataron tu hermano, mejor nos vamos, entonces nos fuimos para Cartagena con toda la familia". (Grupo Focal [G.F.] - Habitante originario del Cesar)

"Yo tenía una finca en Riosucio, tenía 22 reses, tenía gallinas, gallo fino, ahora solo tengo un ternero... El día que salimos de allá, salí solo con una muda de ropa. Hicimos el cruce ocho días en trocha por la selva entre Chocó y Panamá. Eso fue muy duro, mujeres sufriendo para parir en la montaña, se moría la gente. A veces óamos la motosierra y nos quedábamos escondiditos, a esperar que pasara el peligro. Por ahí salimos al Darién". (G.F. - Habitante originario del Chocó)

\section{Caracteristicas socio-demográficas de la población}

En Patio Grande se censaron 30 hogares, lo que permitió recolectar información sobre 129 habitantes. Contrario a los resultados nacionales, en la comunidad habitan mayoritariamente personas del sexo masculino. Mientras que en el país el 51\% de la población son mujeres, en la vereda este grupo sólo representa el 41.1\% y mientras que a nivel nacional el 48\% son hombres, en Patio Grande el dato de presencia masculina llega a 58.9\%.

Debido a las fracturas humanas que genera el desplazamiento y la inexistencia de un crecimiento demográfico natural, Patio Grande presenta una pirámide poblacional con fuertes diferencias por edades y por sexo, en comparación con lo que muestran los municipios colombianos. Como es tradicional en comunidades con altas tasas de reproducción, la vereda posee una pirámide de base amplia, incluso con mayor peso porcentual que los registros nacionales, ya que el grupo etario de menores de 19 años representa el 49.2\% de la 


\section{Gráfico 2. Pirámide poblacional de Patio Grande (2010)}

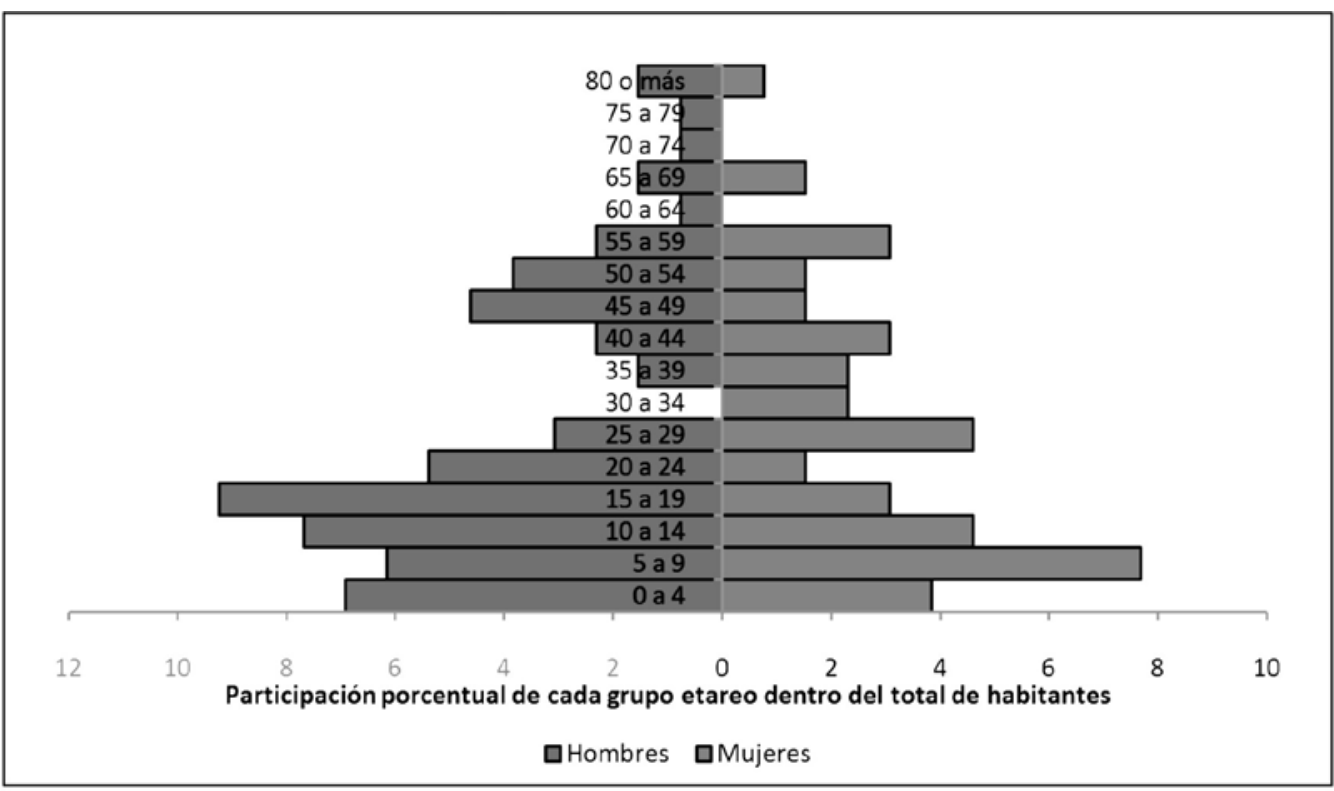

Fuente: Cálculos del autor con base en CRPG - 2010

población, mientras que el Censo Nacional de 2005 arrojó una cifra de 40\% para el mismo grupo. La amplitud de esta base se debe a la mayor cantidad de nacimientos de menores del sexo masculino, de hecho, por cada mujer menor de edad hay 1.5 hombres.

La pirámide poblacional muestra en la parte intermedia una fuerte diferencia con los datos nacionales. Mientras que en Colombia el grupo etario de 20 a 39 años aporta el 30.8\% de la población, en Patio Grande este grupo sólo representa el 20.8\%, dejando ver una pirámide muy estrecha en las edades económicamente más productivas. Sin embargo nuevamente se produce un ensanchamiento piramidal de forma notable a partir de 40 años, comportamiento que es habitual en países con bajas tasas de reproducción. Por ello, aparece una diferencia frente a la demografía colombiana que en el grupo de mayores de 39 años posee el 27\% de la población, mientras que en Patio Grande estos habitantes representan el 30\%. Entonces en la vereda conviven mayoritariamente personas muy jóvenes con personas de edades mayores, lo que representa una carga elevada de sostenimiento económico para los pocos pobladores de edades más productivas, hecho que se mantendrá por lo menos durante los próximos 10 años.

La escasez de mano de obra adulta contribuye a explicar por qué el 14\% de los menores de 19 años se han incorporado rápidamente al trabajo, asistiendo a sus padres o a sus vecinos en calidad de empleados remunerados en algunos 
casos, y no remunerados en otros. De este grupo, la mitad señala estar aún estudiando y el resto abandonó la escuela sin culminar la formación secundaria completa, facilitando la tendencia a la reproducción de la pobreza.

En la parcela mis empleados son mis cuatro hijos, ellos estudian y trabajan, están jornaleando para llevar platica al colegio, sobre todo cuando no viene el transporte. (G.F. - Habitante originario del Chocó).

Ibáñez ha indicado que las características de los hogares desplazados en Colombia muestran que estos enfrentan una alta propensión a ser pobres. Sostiene que las familias pobres colombianas presentan generalmente viviendas con muchos miembros, con alta dependencia económica, con fuerte presencia de niños y ancianos, con alta fecundidad y baja escolaridad, entre otros elementos, situación que se está repitiendo y agravando en los hogares desplazados. Efectivamente al comparar la estructura predominante de los hogares de Patio Grande con los datos nacionales, se encuentra que las familias de la vereda tienen una mayor probabilidad de situarse por debajo de la línea de pobreza que una familia promedio colombiana, tal como se observa en la tabla No 1.

Tabla 1. Estructura de los hogares de Patio Grande (2010)

\begin{tabular}{|l|r|r|}
\hline & Patio Grande & Colombia \\
\hline Tamaño promedio del hogar & 4,4 & 3,9 \\
\hline Promedio por hogar de menores de 14 años & 1.6 & 1.2 \\
\hline Cantidad por hogar de mayores de 65 años & 0.3 & 0.2 \\
\hline Tasa de dependencia & 0.73 & 0.56 \\
\hline Años de educación promedio del jefe o jefa del hogar & 4.5 & 7.6 \\
\hline Analfabetismo en más de 15 & $18.6 \%$ & $6,7 \%$ \\
\hline Tasa de mujeres embarazadas (12 a 50 años) & $18 \%$ & $7.5 \%$ \\
\hline
\end{tabular}

Fuente: Cálculos del autor con base en CRPG - 2010 y Censo Dane - 2005

Los hogares de Patio Grande son relativamente más grandes que el promedio de un hogar colombiano. El tamaño se explica especialmente por la cantidad de menores de 14 años que en promedio hacen parte de cada familia, cifra que tiende a aumentar al tener una tasa de mujeres embarazadas que duplica el nivel nacional y que ha permitido el aumento de la población por natalidad en cuatro nuevos habitantes cada año. Este hecho contribuye a la prolongación de la pobreza, porque provoca una alta tasa de dependencia sobre los miembros económicamente activos de cada familia, situación que es agravada por la baja escolaridad que caracteriza justamente a este grupo poblacional. 


\section{Mercado laboral}

El 75\% de los habitantes de Patio Grande reportan edad para trabajar ${ }^{9}$, de los cuales el 39\% corresponde a mujeres y el 61\% restante a hombres. A su vez, dentro de este total, se encuentra que el $45.4 \%$ manifiesta haber desempeñado una ocupación de carácter remunerativa en la semana anterior a la encuesta, cifra inferior en cinco puntos porcentuales a lo registrado a nivel nacional ${ }^{10}$ en el sector rural.

La tasa de ocupación es ampliamente superior en el grupo de hombres, ya que mientras el 55.9\% de estos estaban trabajando, sólo el 28.9\% de las mujeres reportó haber efectuado actividades remunerativas en la semana anterior. Sin embargo si se incluyen a las mujeres que manifestaron desempeñarse como amas de casa, pero sin remuneración, la cifra del sexo femenino laborando crecería a 50\%. Este elemento es importante para la división del trabajo que funciona en las familias de la comunidad, ya que la generación de ingresos de cada hogar es efectuada desde dos lugares cuya diferencia se correlaciona con el sexo de cada miembro. El primer lugar es la parcela, donde laboran mayoritariamente hombres en actividades relacionadas con la agricultura y el segundo lugar es la propia vivienda, donde las mujeres desarrollan, además de las labores relacionadas con la economía del cuidado, la cría de animales domésticos y la venta de servicios.

La familia es una empresa y cada una cumple su papel. Las mujeres cuidan los gallinitas, los cerdos, los pollitos, prepara los muchachos que van para el colegio. Claro que también hay unas que tiran rula... Ellas juegan un papel fundamental porque si no fuera por ellas, nosotros no fuéramos al monte. Y cuando volviéramos del monte no podríamos volver a ir porque ya estaríamos listos. (G.F. - Habitante originario del Magdalena)

Esta división influye en la distribución de la población ocupada por actividad económica. Se dedican a la agricultura, específicamente a la siembra de yuca, ñame, y maíz el 58.1\% de los trabajadores, de los cuales solo dos personas son mujeres. El segundo sector en importancia, es servicios, que representa el $18.6 \%$ de los ocupados, población mayoritariamente femenina y que se dedica a actividades que efectúan desde las viviendas, tales como venta de llamadas telefónicas, servicios de belleza y oficios domésticos, entre otros. Además se encontró el sector de actividades de comercio con un 16.3\% y el de transporte con un $7 \%$.

${ }^{9}$ Mayores de diez años en zona rural según el DANE. ${ }^{10}$ Las cifras nacionales de empleo corresponden a información del Dane para el

Palobra No. 11. Septiembre de 2009 - Agosto de 2010 
1 El NBI estima la pobreza desde las carencias estructurales del hogar atribuibles principalmente a la falta de acceso a bienes y servicios básicos y a una recurrente insuficiencia de ingresos. ingresos. Las dimensiones son calidad de la vivienda, el hacinamiento, acceso a servicios sanitarios, asistencia escolar y dependencia económica.
Sin embargo, en la semana anterior a la encuesta no todos los pobladores que buscaron trabajo habían logrado vincularse laboralmente. La tasa de desempleo de la comunidad es del 15,4\%, cifra que duplica el registro en el sector rural colombiano que se ubicó en el $7.4 \%$, lo que sugiere que las parcelas de Patio Grande carecen de la capacidad productiva requerida para generar más puestos de trabajo. La escasez de demanda laboral está afectando principalmente a las mujeres, ya que el $26.7 \%$ de las que clasifican como población económicamente activa no tienen empleo, mientras que el registro para este indicador es del 10.8\% en los hombres. Estos resultados son preocupantes porque el desempleo se relaciona de forma directa con la tasa de dependencia y la tasa de pobreza, poniendo en riesgo las posibilidades de estabilización socioeconómica de esta población.

\section{La crisis laboral resulta más grave al evaluar variables sobre calidad del empleo.}

Como es común en las zonas rurales, en Patio Grande son inexistentes los contratos laborales, los reconocimientos de prestaciones sociales, la estabilidad laboral y los salarios superiores al mínimo legal vigente. Vale la pena recurrir a la voz de uno de los pobladores para dimensionar las condiciones laborales actuales de la comunidad:

Los hijos los llevo conmigo a la parcela y les digo, mis hijos esta es una vida muy triste, tirar rula es una vida muy triste, hágale para que vea que eso es duro, y haga por aprender algo en la vida, que esta vaina es tremenda, lo último de la vida, yo creo que este es el peor trabajo, que uno lo hace obligado porque nos quedamos en este ambiente. (G.F. - Habitante originario del Chocó)

\section{Pobreza e indigencia Enfoque directo: Necesidades Básicas Insatisfechas (NBI) ${ }^{11}$}

De acuerdo con los últimos dos censos realizados en Colombia, el porcentaje de hogares con alguna necesidad básica no satisfecha en el sector rural en doce años cayó a una tasa promedio de 1.2\% anual, llegando en el 2005 a ubicarse el porcentaje de pobres por NBI en 53.4\%. Los resultados del censo aplicado en Patio Grande, señalan que la situación en la comunidad es más grave. El 70\% de los hogares no satisfacen al menos una necesidad, lo que los clasifica como pobres, y el 36.7\% no satisface dos o más necesidades, lo que los ubica en situación de miseria.

La dimensión con mayor impacto en el indicador de Patio Grande es la falta de una apropiada vivienda, ya que el $56.7 \%$ de los hogares residen en 
infraestructuras de material inadecuado, donde predomina el tablón, el zinc y la tela en paredes y la tierra y la madera burda en pisos. La segunda variable con más peso es el hacinamiento ${ }^{12}$, debido a que en el $20 \%$ de los hogares conviven 5.2 personas por habitación, cifra notablemente superior al valor máximo permitido para categorizarlo como nivel crítico.

La dificultad de prestar servicios básicos de saneamiento fuera de las zonas urbanas, ocasiona que la metodología del cálculo del NBI en esta necesidad sea relativamente flexible para los hogares rurales. Mientras que para las ciudades un hogar se clasifica como pobre si carece de servicio sanitario o de acueducto, en la zona rural es pobre el hogar que simultáneamente carezca de los dos servicios. Ello permite que comunidades como

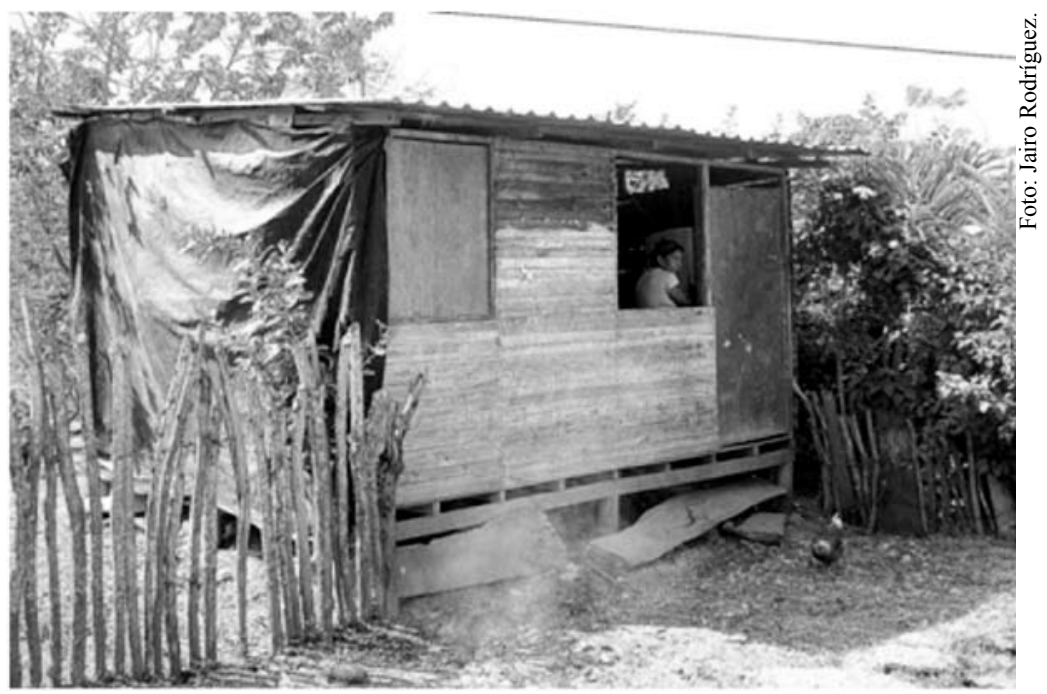

Mujer cocinando en la alcoba. Patio Grande (Bolívar) 2010. Patio Grande cuya única solución de agua es la lluvia recolectada directamente en cada vivienda o en un pozo que acopia parte de ella, no sea denominado pobre por servicios básicos inadecuados si posee un inodoro conectado a poza séptica. En este orden de ideas, en la comunidad el 16.7\% de los hogares presenta carencia de los dos servicios, aunque realmente el 100\% no logra acceder a una solución adecuada de agua potable.

El indicador de dependencia económica en el NBI define como no pobre, el hogar cuyo jefe o jefa tenga mínimo tres años de educación primaria y que paralelamente por cada tres personas que lo habitan, al menos una trabaje. Este indicador arroja en Patio Grande que el 13.3\% de los hogares son pobres por alta dependencia económica. Sin embargo, se debe señalar que al revisar las dos condiciones de forma separada, se encuentra que el 30\% de los jefes o jefas de hogar no alcanzaron a aprobar dos años de primaria y que en el $40 \%$ de los hogares conviven más de tres personas por cada trabajador o trabajadora, lo cual denota una distancia muy leve de las familias de Patio Grande a los mínimos exigidos en el indicador de NBI.

La variable de capital humano que consulta por la asistencia escolar de menores ubicados entre los siete y los doce años produce un resultado positivo

${ }^{12}$ Se entiende hacinamiento crítico cuando en una vivienda comparten más de tres personas un cuarto (incluyendo sala y comedor) 
en la comunidad, ya que de acuerdo a la información suministrada por los informantes del cuestionario indicaron que todos los niños y niñas de dicha edad están asistiendo a alguna institución educativa. Cabe indicar que la asistencia se encuentra en riesgo permanente en el caso de los menores que deben asistir a la secundaria en la sede principal de las instituciones, ya que el transporte que suministra el Estado es inestable, exigiendo a los padres de familia destinar con frecuencia un recurso adicional para ello, comprometiendo otras necesidades básicas.

Vea, yo tengo cuatro hijos en el colegio, cuando el carro no viene, a veces uno no tiene para pagarle la mototaxi, entonces si uno les da para el transporte, ese día no hay para comer. (Grupo Focal - Habitante originario del Chocó)

El NBI capta variables que le apuntan a la pobreza estructural, pero se altera insignificantemente por hechos coyunturales como la pérdida del empleo, la caída en los ingresos o las recesiones económicas. De tal forma que si un hogar satisface las necesidades básicas incluidas en el indicador, pero sus ingresos no alcanzan para alimentarse, el hogar no calificaría como pobre. Otro defecto de la medición de la pobreza por este enfoque es que no es por su escala característica eminentemente nominal, resulta imposible determinar qué tanto se alejan o se acercan los pobres de la satisfacción de todas sus necesidades básicas (brecha de la pobreza).

\section{Enfoque indirecto: Línea de pobreza (LI)}

Los efectos coyunturales mencionados logran ser captados por el método de línea de pobreza, fundamentado en la definición de la capacidad adquisitiva del hogar en el momento de la recolección de la información. De forma simplificada definir la línea de pobreza requiere calcular el valor de una canasta alimentaria que garantice los mínimos calóricos (establecidos por la FAO) por persona, valor denominado línea de indigencia. Posteriormente se adiciona el gasto por consumir los bienes y servicios básicos no alimentarios (vivienda, salud, educación, transporte, vestido, etc.), la suma de los dos gastos se denomina línea de pobreza. Las personas cuyos ingresos no superen la línea son denominados pobres y aquellos que no superen el valor de la canasta alimentaria se clasifican como indigentes.

Teniendo en cuenta que en el sector rural, parte de los alimentos pueden ser obtenidos por medio de la recolección y la caza, el Departamento Nacional de 
Planeación estableció para diciembre de 2009 la línea de indigencia para este sector en \$95.319 mensuales por persona y la línea de pobreza en \$204.448 mensuales por persona. Con este referente el DNP determinó que en dicho año la tasa de indigencia en el campo fue de $29.1 \%$ y la tasa de pobreza de $64.3 \%$.

Los datos de Patio Grande resultan más desalentadores. El ingreso promedio por persona de la comunidad es de $\$ 63.955$, valor que representa solo el $67 \%$ del mínimo requerido para obtener una canasta alimentaria básica y el 31\% de lo necesario para que alguien sea considerado como no pobre. De forma individual el 93,3\%\% de los habitantes perciben ingresos inferiores a la línea de pobreza, cifra que representa 3,2 veces el dato nacional y que significa que solo ocho personas de la población han superado la meta definitiva establecida por la Corte Constitucional para la consolidación económica de un desplazado. Además existen serias dificultades para que el resto de los habitantes alcance dicha meta, ya que la brecha de pobreza indica que el ingreso promedio de este grupo se aleja de la línea de pobreza en un 70\% y la distribución de ingresos muestra que el 50\% más pobre de Patio Grande recibe sólo el $24 \%$ de los ingresos de toda la comunidad.

La incidencia de pobreza coincide con el indicador de pobreza subjetiva captado a través de la pregunta sobre suficiencia de los ingresos recibidos frente a los gastos básicos que se presentan en la tabla 2 y que evidencia, nuevamente, un rezago importante frente a lo registrado en el sector rural colombiano.

\section{Tabla 2. Apreciación de los hogares de Patio Grande sobre la suficiencia de los ingresos}

\begin{tabular}{|l|c|c|}
\hline & $\begin{array}{c}\text { Patio } \\
\text { Grande }\end{array}$ & $\begin{array}{c}\text { Colombia - } \\
\text { Zona Rural }\end{array}$ \\
\hline $\begin{array}{l}\text { Son más que suficientes para cubrir los gastos básicos del ho- } \\
\text { gar? }\end{array}$ & $0 \%$ & $4 \%$ \\
\hline No alcanzan para cubrir los gastos básicos del hogar? & $90 \%$ & $51 \%$ \\
\hline Son suficientes para cubrir los gastos básicos del hogar? & $10 \%$ & $44 \%$ \\
\hline
\end{tabular}

Fuente: Cálculos del autor con base en CRPG - 2010 y Censo Dane - 2005

Estos resultados son consecuencia de los bajos ingresos laborales que percibe la población ocupada en las actividades económicas mencionadas con anterioridad. Ninguno de los trabajadores o trabajadoras de Patio Grande 
recibe un salario igual o superior al mínimo legal vigente y el 73\% recibe por su empleo solamente la mitad de dicho salario.

\section{Gráfico 3. Distribución de la población ocupada de Patio Grande según ingreso laboral recibido en el último mes}

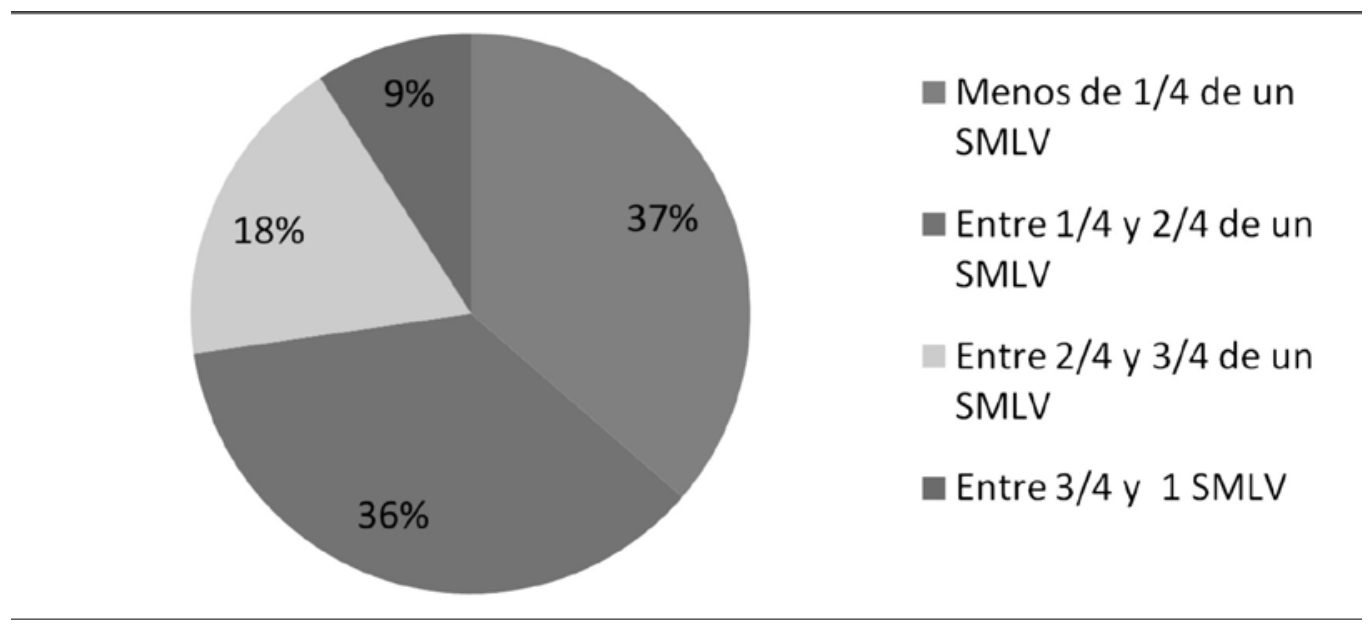

Fuente: Cálculos del autor con base en CRPG - 2010

Los precarios ingresos laborales influyen igualmente en la alta tasa de indigencia, ya que el 76,6\% de la comunidad recibe mensualmente un monto inferior del valor monetario de la canasta básica alimentaria del sector rural, de tal forma que después de seis años de reasentamiento, menos de una cuarta parte de la población de Patio Grande ha logrado superar la meta inicial de consolidación socioeconómica. Situación que se ve agravada por el hecho de que el ingreso promedio de los habitantes en condición de indigencia no alcanza siquiera para adquirir la mitad del valor de dicha canasta.

Un nivel de indigencia tan alto implica que la situación alimentaria de la comunidad esté en constante riesgo. Por falta de alimentos o dinero en la semana anterior a la recolección de información, el 44.1\% dejó de consumir al menos una comida (desayuno, almuerzo o cena), el 28.3\% dejó de consumir más de seis comidas y el $4.7 \%$ se alimentó diariamente con una sola comida.

Las comidas son, una a las 10 y otra a las 3:30 y a dormir temprano. A veces toca comer solo dos veces, pero hay gente que está pasando más hambre. Hay veces que uno se organiza en la mañana para ir al trabajo y le dice la mujer a uno, ve que tienes que venirte un poco temprano porque aquí no hay nada que comer y no te me vas a desmayar. (G. F. - Habitante originario de Antioquia) 
A los problemas en la cantidad de alimentos, hay que sumar la inadecuada calidad de los nutrientes recibidos. Ante la pregunta sobre el tipo de alimentos que predominan en el menú de los hogares, se encontró que consumen fundamentalmente productos de pan coger que tienen altos componentes energéticos, tales como el arroz, la yuca, el plátano y el ñame, pero sólo el 49\% afirma que logra incorporar dentro de su alimentación semanal productos proteínicos de origen animal que tienen un alto valor biológico. Este hecho tiene importantes efectos sobre el crecimiento y la capacidad de aprendizaje en los menores de edad, y se ha hecho evidente en las deficiencias de peso y talla que padecen el 12\% de los menores de 12 años y que los ubica en situación de desnutrición ${ }^{13}$.

El enfoque de medición vía ingresos se sustenta en que la falta de renta puede poner en riesgo la satisfacción de necesidades básicas, pero debe tenerse en cuenta que la pobreza es un asunto multidimensional y que la relación entre ingresos y eficacia de satisfactores puede variar entre personas, dependiendo de características individuales y sociales que les son inherentes, por eso, para algunos individuos puede ser más difícil convertir renta en capacidades (Sen, 1992).

Con el fin de solventar parcialmente la anterior dificultad se utilizó el método de Rubén Katzman ${ }^{14}$ que integra el enfoque de NBI y de LP en una tabla de contingencia que organiza la población en cuatro grupos diferentes de pobreza dependiendo de la situación del hogar frente a los dos indicadores. El autor define como Pobreza crónica cuando el hogar es clasificado pobre bajo NBI y bajo LP, Pobreza inercial cuando el hogar es pobre sólo por NBI, Pobreza coyuntural cuando el hogar es pobre sólo por LP y el grupo de No pobres cuando no clasifican como tal, por ninguno de los dos indicadores (1989).

Teniendo en cuenta los reducidos ingresos de la comunidad y las metas fijadas por la Corte Constitucional que se han mencionado anteriormente, el estudio aplicó el método de integración no sólo para la medición de pobreza de Patio Grande, también es importante cruzar los datos de indigencia con los hogares en condición de miseria. Los principales resultados de este ejercicio son:

๑) Empleando los dos indicadores ningún hogar de Patio Grande ha logrado superar la meta definitiva de la Corte.

๑) El 30\% de los hogares satisface sus necesidades básicas, pero el bajo nivel de ingreso que reciben pone en riesgo que dicha satisfacción sea

${ }^{13}$ Fuente: Análisis del cuadro de registro de pesaje, talla, vacunación de niños y niñas en la comunidad de Patio Grande efectuado por el Observatorio del Desplazamiento Forzado de la Plazamiento Forzado de la Uatio Grande 2010. Patio Grande - 2010. ${ }^{14}$ Se debe señalar que, al ser indicador agregado, el método de integración asumido no resuelve del todo el problema planteado por Sen. En el informe final de la investigación se incluyen la investigacion se incluyen variables adicionales para tomar nota de las variacio-
nes interpersonales e intersociales. 
permanente (Pobreza coyuntural).

๑) Hay un 6.6\% que recibe ingresos suficientes para cubrir gastos básicos, pero padecen condicionamientos estructurales que han impedido que los ingresos se conviertan en satisfacción efectiva de las necesidades básicas (Pobreza inercial).

—) El $63.3 \%$ de los hogares están sometidos a privaciones en sus necesidades básicas debido a condiciones estructurales que se prolongan indefinidamente porque los ingresos no alcanzan para adquirir los satisfactores mínimos requeridos (Pobreza crónica).

\) El 40\% de los hogares deja de satisfacer una necesidad básica y sus bajos niveles de ingreso ponen en riesgo la satisfacción de las restantes (Indigencia coyuntural).

๑) El 6.6\% reciben ingresos que le permiten obtener una canasta básica alimentaria, pero aun padecen una situación crítica en la satisfacción de sus necesidades básicas (Indigencia inercial).

๑) El 30\% de los hogares son los más pobres dentro de los pobres, no logran satisfacer dos o más necesidades básicas, hecho que se mantiene constante en el tiempo porque los ingresos que perciben no alcanzan siquiera para comprar la canasta mínima alimentaria (Indigencia crónica).

\section{Porqué no logran generar ingresos adecuados? Posibles explicaciones}

En algunas variables de este último grupo, se pueden encontrar elementos que ayudan explicar la pobreza extrema de la comunidad. Este 30\% se compone de hogares densamente poblados, que concentran el $43 \%$ de los habitantes de la población total. Los hogares están compuestos mayoritariamente por personas jóvenes, de hecho el 56\% de los menores de 12 años de Patio Grande se encuentran en este grupo, lo que resulta preocupante al determinar el promedio de comidas dejadas de consumir por persona (4.5 en la última semana), que indica que más de la mitad de la población infantil está en riesgo de inanición. Además las expectativas de generación de ingresos son mínimas. La escolaridad del jefe o jefa de hogar sólo alcanza los 3,2 años, la tasa de analfabetismo de mayores de 15 años es de 33\%, de la población económicamente activa aparece desempleada el $37 \%$ y el ingreso promedio por persona solo llega a \$41.000 mensuales. El 80\% de la población trabajadora de este grupo de indigencia crónica se dedica a la agricultura, cifra superior al resultado promedio de la comunidad que reporta casi la mitad de los trabajadores en otros sectores económicos. 


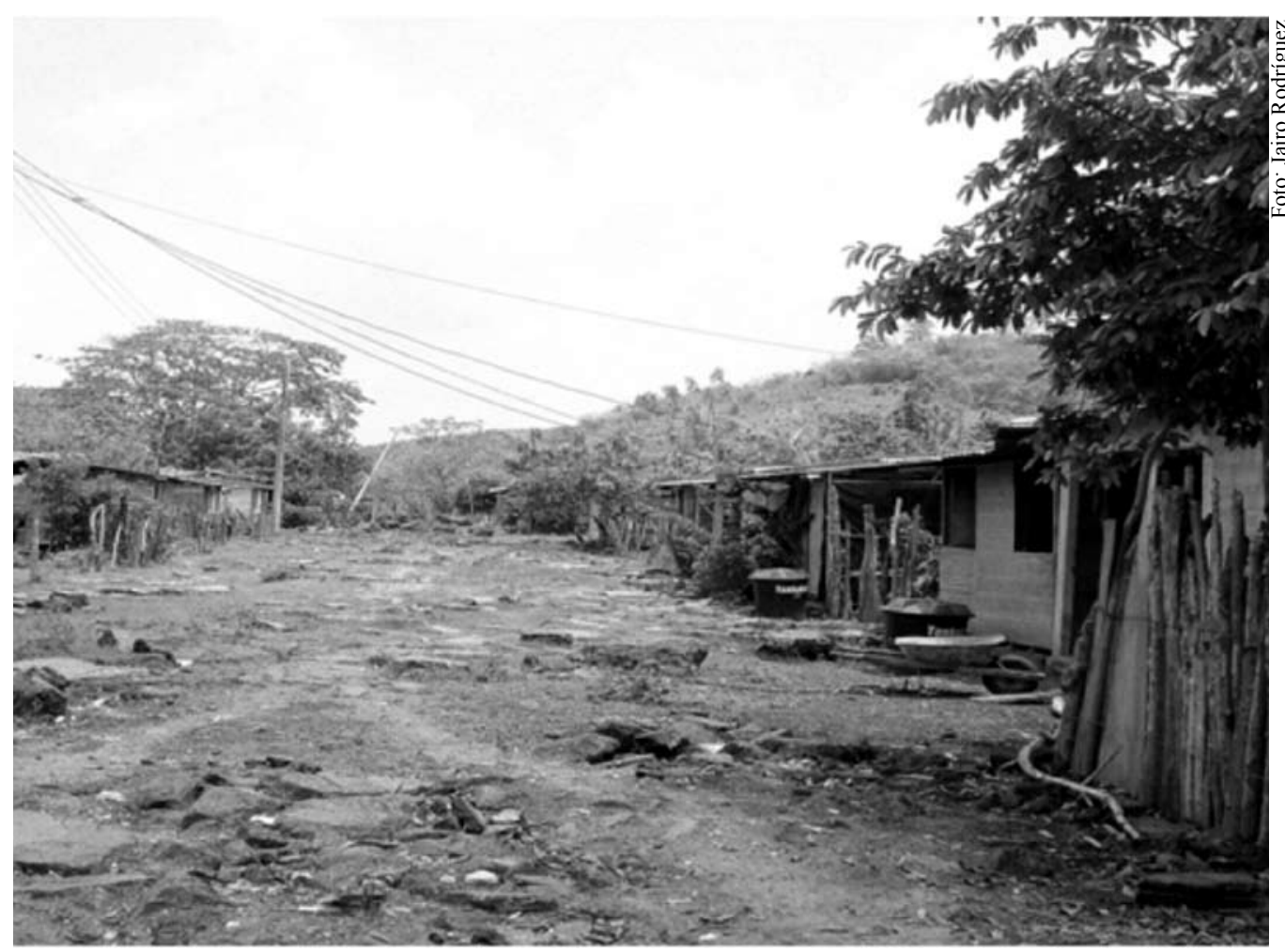

Calle principal. Patio Grande (Bolívar) 2010.

No es suficiente con entregar la tierra, los habitantes manifestaron haber perdido animales, herramientas de trabajo incluso capital humano, pero no perciben que el Estado haya reparado estos recursos y no hay resultados económicos que evidencien el funcionamiento efectivo de algún programa de proyectos productivos. Si bien han recibido en algunos momentos capacitación y apoyo para el desarrollo de proyectos, los habitantes señalan que no ha sido suficientemente útil, ya que carecen de capacidades (en el sentido de Sen, 1996) y recursos productivos que permitan aprovechar la formación recibida, acceder a mejores empleos y lograr la extracción efectiva de las ganancias de la tierra. Por ello, los productos que obtienen de las parcelas no gozan de ventajas competitivas en los mercados cercanos que les proporcione algún poder de negociación.

Nos han capacitado bastante. Aquí ha venido cualquier entidad que usted se imagine. Sobre socialización, como vivir en comunidad, capacitaciones para criar gallinas, pero no hay huevos. En piscicultura, pero no hay agua ni herramientas. Mire nosotros sabemos pescar, lo que no tenemos es la atarraya, a nosotros nos gusta trabajar, queremos trabajar, pero no tenemos herramientas (G.F. - Habitante originario de Antioquia). 
En este sentido, uno de los problemas que identifican como prioritario es la ausencia de una infraestructura básica de riego. Además de carecer de un flujo constante de agua, no logran aprovechar la poca que obtienen de la lluvia para dirigirla de forma controlada a las parcelas y abastecerse en tiempo seco. Hechos como estos, obligan al campesino a depender económicamente de la situación climática, lo que termina generando ingresos inestables, que hace que los habitantes se salten de la pobreza a la indigencia dependiendo la época del año en que se consulte.

Hemos estado pasando por una crisis muy pesada, el año pasado perdimos toda la cosecha... Uno produce en el invierno, cuando llega el verano uno consume la cosecha. Pero el verano ya pasó, ya nos hemos comido lo que hicimos en el verano y el hambre queda... Los cultivos que están saliendo se siembran en una loma, pero solo se salvan si les cae agua, si no, la producción se perdió. (G.F. - Habitante originario del Magdalena)

El crédito, como en todo tipo de empresas, es una herramienta que posibilita la ampliación de la capacidad productiva, pero el acceso de la comunidad a esta opción también ha presentado dificultades. El tipo de titulación condicionada sobre el único activo que las familias proponen como garantía, la tierra, no ha sido aceptado por el sector financiero que funciona en la cabecera municipal. De la misma forma, la ausencia de redes de autoayuda, restringe la posibilidad de identificar codeudores, otro requisito básico de la banca. De esta forma, el sistema financiero no ha sido flexible y los requisitos que solicita para otorgar créditos se han convertido en barreras. Por ello los habitantes perciben que la banca no está ofreciendo créditos que reconozcan la situación especial en la que se encuentra la vereda.

Tenemos un semitítulo de esta tierra que no nos respalda como propietario. Porque uno lo lleva al banco, y uno lo muestra y le dicen esto no. Tiene que independizarse, estar a paz y salvo... Nosotros hemos solicitado crédito en los bancos pero como no somos de acá, aquí nadie nos conoce, pero nos exigen fiador, y quién le va a servir de fiador a una persona desconocida. (G.F. - Habitante originario de Antioquia)

Por otra parte las diferencias socio demográficas mencionadas con anterioridad pueden estar obstaculizando la conformación de una organización comunitaria 
fuerte con capacidad de gestión que permita entre otras cosas, orientar de forma colectiva el uso de la tierra para aprovechar economías de escala y proporcionar un mayor poder de negociación ante los mercados a los que se accede y ante la administración departamental y local. Pero las diferencias no sólo se producen internamente, ya que efectivamente ninguno de los residentes de Patio Grande es originario de San Jacinto o de El Carmen de Bolívar y esto provoca distancias y choques culturales con las poblaciones vecinas y el gobierno municipal. Su condición de reasentados ocasiona que los vínculos políticos, económicos, culturales o sociales con los municipios cercanos sean efímeros, discriminatorios o inexistentes. Por eso la comunidad, no solo carece de redes fuertes de autoayuda formal e informal, sino que muestra una ausencia de redes sociales con el exterior de la vereda y que son necesarias para lograr el acceso efectivo a los espacios de producción, distribución y comercialización, así como para participar en la toma de decisiones municipales que influyan en el destino de la comunidad.

Aquí hay gente de todas partes del país, entonces son costumbres muy distintas, entonces es muy verraco que venga hoy el alcalde de San Jacinto, que la costumbre es sembrar yuca y ñame y yo no sé sembrar eso, yo entiendo y me crié fue en el ganado. Nosotros no podemos tener la tradición agropecuaria de San Jacinto, de sembrar yuca, ñame. Aquí nadie es de San Jacinto. Pero me queda muy difícil salir adelante cambiándome a otra actividad,... Nuestro líder va solo pero nadie le presta atención, allá es una sola mamadera de gallo, coge para un lado coge para el otro, pero el solo no logra hacer nada. (G.F. - Habitante originario de Antioquia)

Finalmente, para entender las condiciones económicas que deben enfrentar los habitantes de Patio Grande, no se puede desconocer la situación actual del campo colombiano que presenta una "crisis semipermanente" que ha empobrecido a los pequeños agricultores y desruralizado el país (Fajardo, 2002). Diversos autores ${ }^{15}$ señalan como principales causas del problema agrario: la concentración, subexplotación y sobreexplotación la tierra, la concepción de la tierra como recurso especulativo ${ }^{16}$, la competencia desigual frente a potencias agrícolas, los cultivos ilícitos, el acceso injusto a los mercados de insumos, de créditos y de productos, poca tecnificación, la informalidad del empleo rural que aumenta el diferencial frente a los salarios urbanos, baja escolaridad del campesino, ausencia de una política de sostenimiento de la economía campesina y el interés en la sustitución de

15 Ver por ejemplo textos de Jesús Bejarano, Absalón Machado o Darío Fajardo. ${ }^{16}$ De acuerdo a la información ofrecida en entrevistas por habitantes, algunas familias han optado por vender las tierras a precios que representan la cuarta parte del valor señalado originalmente en los títulos. Se indicó que algunos de los compradores son terratenientes de la región que están ampliando sus activos con fines pecuarios, principalmente. 
cultivos transitorios que respaldan la seguridad alimentaria (cultivos de ciclo corto como los que se producen en Patio Grande) por cultivos permanentes orientados fundamentalmente a los mercados internacionales. Aunque los campesinos de Patio Grande presentan algunos de estos hechos, los datos evidencian que estos padecen mayor situación de vulnerabilidad frente al habitante rural colombiano.

\section{Conclusiones}

Siete años después del reasentamiento persisten los riesgos de empobrecimiento que identifica Cernea y que fueron resultado tanto del desplazamiento forzado como de las insuficiencias del proceso de reubicación. Si bien los hogares recibieron tierra, estos no acceden a los demás medios de producción, insumos y herramientas requeridas para generar ingresos adecuados.

Aunque las familias recuperaron parcialmente su vivienda, las condiciones actuales de ésta, evidencia la pobreza estructural que ha venido soportando la comunidad. Por otro lado, solo una cuarta parte de los hogares logran generar ingresos suficientes para consumir una canasta básica alimentaria, meta parcial de la Corte Constitucional, pero su nivel de ingresos es tan bajo e inestable que presentan altas posibilidades de caer frecuentemente debajo de la línea de indigencia. El resto de las familias reciben ingresos que las clasifican como de extrema pobreza, lo que implica que se encuentran en constante riesgo de inanición y que no se logra satisfacer adecuadamente el resto de necesidades básicas.

Además la población no logra tener acceso a bienes colectivos necesarios para satisfacer necesidades básicas e impulsar el desarrollo. No reciben agua potable, carecen de infraestructura de riego para las parcelas, no tienen garantizado el transporte diario para asistir a la escuela, la oferta de espacios físicos comunes es precaria.

Sin embargo parte de estos resultados no son exclusivos de Patio Grande, lo que se encuentra en la vereda son los síntomas de la crisis semipermanente que subsiste en el campo colombiano, pero que se exacerba en el reasentamiento porque sus pobladores han padecido el quiebre de su tejido social y están sobreviviendo en condiciones enormemente más vulnerables que el campesino promedio colombiano. 
Por todo esto, ninguno de los hogares reasentados ha logrado superar la pobreza medida de forma integrada por NBI y LP, por lo tanto ningún hogar ha logrado alcanzar los elementos mínimos de dignidad y estabilización socioeconómica que permita calificarlo como no desplazado. Ello implica que el Estado no puede abandonar las comunidades desplazadas y asumir que reubicar a la población es suficiente para el restablecimiento de los derechos. Los efectos humanitarios de la violencia, la precariedad financiera e institucional de muchos municipios colombianos y la crisis campesina exigen del Estado un mayor esfuerzo en la reintegración, acompañamiento y estabilización socioeconómica de poblaciones varias veces marginadas como la de Patio Grande.

\section{BIBLIOGRAFIA}

ACNUR. (2004). Manual de reasentamiento. Ginebra. Alto Comisionado de las Naciones Unidas para los Refugiados.

CERNEA, Michael. (1997). El modelo de riesgos y reconstrucción para el reasentamiento de poblaciones desplazadas. Washington: Banco Mundial.

CODHES. (2000). "En la Miel no todo es dulzura". En PARTRIDGE. William. Reasentamiento en Colombia. Bogotá: Banco Mundial.

Corte Constitucional. (2003). Sentencia T-602. Bogotá.

Corte Constitucional. (2004) Sentencia T-025. Bogotá.

DANE. Censo 2005.

FAJARDO, Darío. (2002). Para sembrar la paz hay que aflojar la tierra. Bogotá: Universidad Nacional de Colombia.

GARAY, Luis y otros. (2008). Verificando el cumplimiento de los derechos. Bogotá: Codhes.

IBÁÑEZ, Ana. (2006). “¿Cómo deteriora el desplazamiento forzado el bienestar de los hogares desplazados?: Análisis y determinantes de bienestar en los municipios de recepción". En Documento Cede, No 26. Bogotá: Universidad de los Andes.

INSTITUTO LATINOAMERICANO DE SERVICIOS LEGALES ALTERNATIVOS. (2006). Desplazamiento y retorno. Balance de una política. Bogotá: ILSA.

JIMÉNEZ, Sandro y otros. (2008). Desplazados. Víctimas en permanente transición. Cartagena: Universidad San Buenaventura.

KATZMAN, Rubén. (1989) "La heterogeneidad de la pobreza: el caso de Montevideo" En Revista de la Cepal No 37. Santiago de Chile. Cepal

Palubra No. 11. Septiembre de 2009 - Agosto de 2010 
MEJIA, María. (2000). "La experiencia colombiana en reasentamiento". En PARTRIDGE, William. Reasentamiento en Colombia. Bogotá: Banco Mundial.

MUGGAH, Robert. (2000). "Through the developmentalist's looking glass: Conflict induced displacement and involuntary resettlement in Colombia". En Journal of refugee studies. Vol 13. No 2. Oxford.

NETHERLANDS INTERDISCIPLINARY DEMOGRAPHIC INSTITUTE. (2006). Millenium development goals: Analysis of peoples to the concern of UNHCR. La Haya. NIDI.

SEN, Amartya. (1996). "Capacidad y Bienestar". En: la calidad de vida (compilador). México. Fondo de Cultura Económica.

SEN, Amartya. (1992) "Sobre conceptos y medidas de pobreza". En Comercio Exterior. vol. 42. núm. 4. México. 